\title{
Statistical properties of kinetic-scale magnetic holes in terrestrial space
}

\author{
ShuTao Yao ${ }^{1,2}$, ZongShun Yue', QuanQi Shi1 ${ }^{*}$, Alexander William Degeling ${ }^{1}$, HuiShan Fu ${ }^{3}$, AnMin Tian ${ }^{1}$, Hui Zhang ${ }^{4}$,

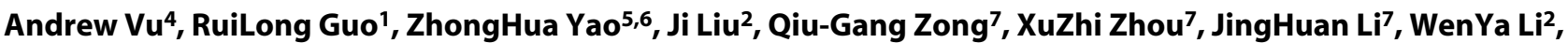 \\ HongQiao Hu${ }^{8}$, YangYang Liư ${ }^{3}$, and WeiJie Sun ${ }^{9}$ \\ 1Shandong Provincial Key Laboratory of Optical Astronomy and Solar-Terrestrial Environment, Institute of Space Sciences, Shandong University, Weihai \\ Shandong 264209, China; \\ 2 State Key Laboratory of Space Weather, National Space Science Center, Chinese Academy of Sciences, Beijing 100190, China; \\ ${ }^{3}$ School of Space and Environment, Beihang University, Beijing 100191, China; \\ ${ }^{4}$ Physics Department and Geophysical Institute, University of Alaska Fairbanks, Fairbanks, AK, 99775, USA; \\ ${ }^{5}$ Key Laboratory of Earth and Planetary Physics, Institute of Geology and Geophysics, Chinese Academy of Sciences, Beijing 100029, China; \\ ${ }^{6}$ Laboratoire de Physique Atmosphérique et Planétaire, STAR Institute, Université de Liège, Liège, B-4000, Belgium; \\ ${ }^{7}$ School of Earth and Space Sciences, Peking University, Beijing 100871, China; \\ 8SOA Key Laboratory for Polar Science, Polar Research Institute of China, Shanghai 200136, China; \\ ${ }^{9}$ Department of Climate and Space Sciences and Engineering, University of Michigan, Ann Arbor, Ml, 48109, USA

\section{Key Points:} \\ - Most KSMHs are locally generated in the magnetosheath, rather than advected with the solar wind. \\ - $\mathrm{KSMHs}$ are more likely to be generated downstream of the quasi-parallel shock, indicating the importance of turbulence in their \\ generation. \\ - The scale-size of KSMHs is smaller near the subsolar magnetosheath than along the flanks, indicating they may be affected by the \\ magnetosheath pressure environment.
}

Citation: Yao, S. T., Yue, Z. S., Shi, Q. Q., Degeling, A. W., Fu, H. S., Tian, A. M., Zhang, H., Vu, A., Guo, R. L., ... and Sun, W. J. (2021). Statistical properties of kinetic-scale magnetic holes in terrestrial space. Earth Planet. Phys., 5(1), 63-72. http://doi.org/10.26464/epp2021011

\begin{abstract}
Kinetic-scale magnetic holes (KSMHs) are structures characterized by a significant magnetic depression with a length scale on the order of the proton gyroradius. These structures have been investigated in recent studies in near-Earth space, and found to be closely related to energy conversion and particle acceleration, wave-particle interactions, magnetic reconnection, and turbulence at the kineticscale. However, there are still several major issues of the KSMHs that need further study — including (a) the source of these structures (locally generated in near-Earth space, or carried by the solar wind), (b) the environmental conditions leading to their generation, and (c) their spatio-temporal characteristics. In this study, KSMHs in near-Earth space are investigated statistically using data from the Magnetospheric Multiscale mission. Approximately 200,000 events were observed from September 2015 to March 2020 . Occurrence rates of such structures in the solar wind, magnetosheath, and magnetotail were obtained. We find that KSMHs occur in the magnetosheath at rates far above their occurrence in the solar wind. This indicates that most of the structures are generated locally in the magnetosheath, rather than advected with the solar wind. Moreover, KSMHs occur in the downstream region of the quasi-parallel shock at rates significantly higher than in the downstream region of the quasi-perpendicular shock, indicating a relationship with the turbulent plasma environment. Close to the magnetopause, we find that the depths of KSMHs decrease as their temporal-scale increases. We also find that the spatial-scales of the KSMHs near the subsolar magnetosheath are smaller than those in the flanks. Furthermore, their global distribution shows a significant dawn-dusk asymmetry (duskside dominating) in the magnetotail.
\end{abstract}

Keywords: kinetic scale; magnetic hole; magnetic dip; electron vortex; turbulence

\section{Introduction}

Magnetic holes (MHs) are structures characterized by a significant

Correspondence to: Q. Q. Shi, sqq@sdu.edu.cn

Received 16 SEP 2020; Accepted 26 NOV 2020.

Accepted article online 25 DEC 2020.

(C)2021 by Earth and Planetary Physics. magnetic depression, and have been widely observed in space plasmas. These structures were first identified in the solar wind (Turner et al., 1977), and were subsequently observed frequently in the planetary magnetosheath (e.g., Cattaneo et al., 1998; Balikhin et al., 2009; Tsurutani et al., 2011; Yao ST et al., 2017), in the magnetotail (e.g., Ge YS et al., 2011; Yao ST et al., 2016; Zhang XJ et al., 2017), in the magnetospheric cusp (Shi QQ et al., 2009; Jasin- 
ski et al., 2017), and even in the magnetosphere of comets (Russell et al., 1987; Plaschke et al., 2018). They have been identified under various names according to their generation mechanisms and property features, for example, "magnetic dips", "magnetic decreases", "mirror modes", and "solitary waves" (e.g., Song P et al., 1992, 1994; Baumgärtel, 1999; Lucek et al., 1999; Horbury et al., 2004; Stasiewicz, 2004; Tsurutani et al., 2011; Yao ST et al., 2018b; Tian AM et al., 2018, 2020; Zhang L et al., 2018; Treumann and Baumjohann, 2019; Wang GQ et al., 2020a; Kitamura et al., 2020). Of these terms, the first two describe the observable phenomenon, while the last two emphasize the generation mechanism and nature.

Kinetic-scale magnetic holes (KSMHs), structures with a significant magnetic depression within the proton gyroradius scale, have attracted much attention in recent years. These structures were first identified in the Earth's magnetotail by Ge YS et al. (2011) and Sun WJ et al. (2012). Various possible generation mechanisms have been proposed, including mirror modes, tearing structures, solitary waves, and ballooning/interchange instabilities (Balikhin et al., 2012; Ji XF et al., 2014; Sundberg et al., 2015; Yao ST et al., 2016; Li ZY et al., 2016; Shustov et al., 2019). Zhang XJ et al. (2017) found that KSMHs can modulate electron cyclotron harmonic waves, and are important for the coupling of Earth's magnetosphere and ionosphere. Using the high temporal resolution data collected onboard NASA's Magnetospheric MultiScale (MMS) mission (Burch et al., 2016), KSMHs associated with electron vortices were observed in the magnetosheath by Yao ST et al. (2017). The electron vortex was found to be due to the combination of electron diamagnetic motion and $E \times$ X motion (Yao ST et al., 2017; Li $\mathrm{JH}$ et al., 2020a). Inside the KSMHs, the flux of lower energy electrons was decreased while that of higher energy electrons was in- creased. This is evidence of electron acceleration inside the KSMHs. A schematic of the KSMHs is shown in Figure 1, accompanied by a typical event observed in the magnetosheath. The scales, boundaries (Liu H et al., 2019a, b), and topologies (Liu YY et al., 2020) of these KSMHs were studied further by applying an innovative particle sounding technique (Zong Q-G et al., 2004), and second-order Taylor expansion (SOTE) method (Liu YY et al., 2019). The propagation, contraction, and expansion of these KSMHs were recently investigated by Yao ST et al. (2020a) based on multi-spacecraft analysis methods (Shi QQ et al., 2005, 2006, 2019; Xiao T et al., 2015; Rezeau et al., 2018; Wang MM et al., 2020). Li JH et al. (2020b) further analyzed the particle behavior and associated distribution functions during the kinetic evolution of the KSMHs. Similar events have also been reported in simulations (Haynes et al., 2015; Roytershteyn et al., 2015) and observations (Huang SY et al., 2017a, b). These structures, including recently reported kinetic-scale flux ropes (Huang SY et al., 2016; Matsui et al., 2019; Sun WJ et al., 2019; Wang SM et al., 2019; Yao ST et al., 2020b) and kinetic-scale magnetic dips and peaks (Hellinger and Štverák, 2018; Stawarz et al., 2018; Yao ST et al., 2018a; Hoilijoki et al., 2019), are new types of coherent structures found in turbulent plasmas, and play important roles in the cascade of turbulence from ion to electron scales (e.g., Huang J et al., 2019; Lucek et al., 2005; Karimabadi et al., 2014; Sahraoui et al., 2020; Shang WS et al., 2020). Yao ST et al. (2019a) found that these KSMHs are coupled with electron cyclotron waves, electrostatic solitary waves, and whistler mode waves (Li Z et al., 2019). The observations revealed that electron beams and temperature anisotropy within KSMHs provide free energy to generate such waves, implying that the KSMHs transfer energy at kinetic scales in turbulent magnetosheath plasmas. The coupling of $\mathrm{KSMHs}$ with whist-

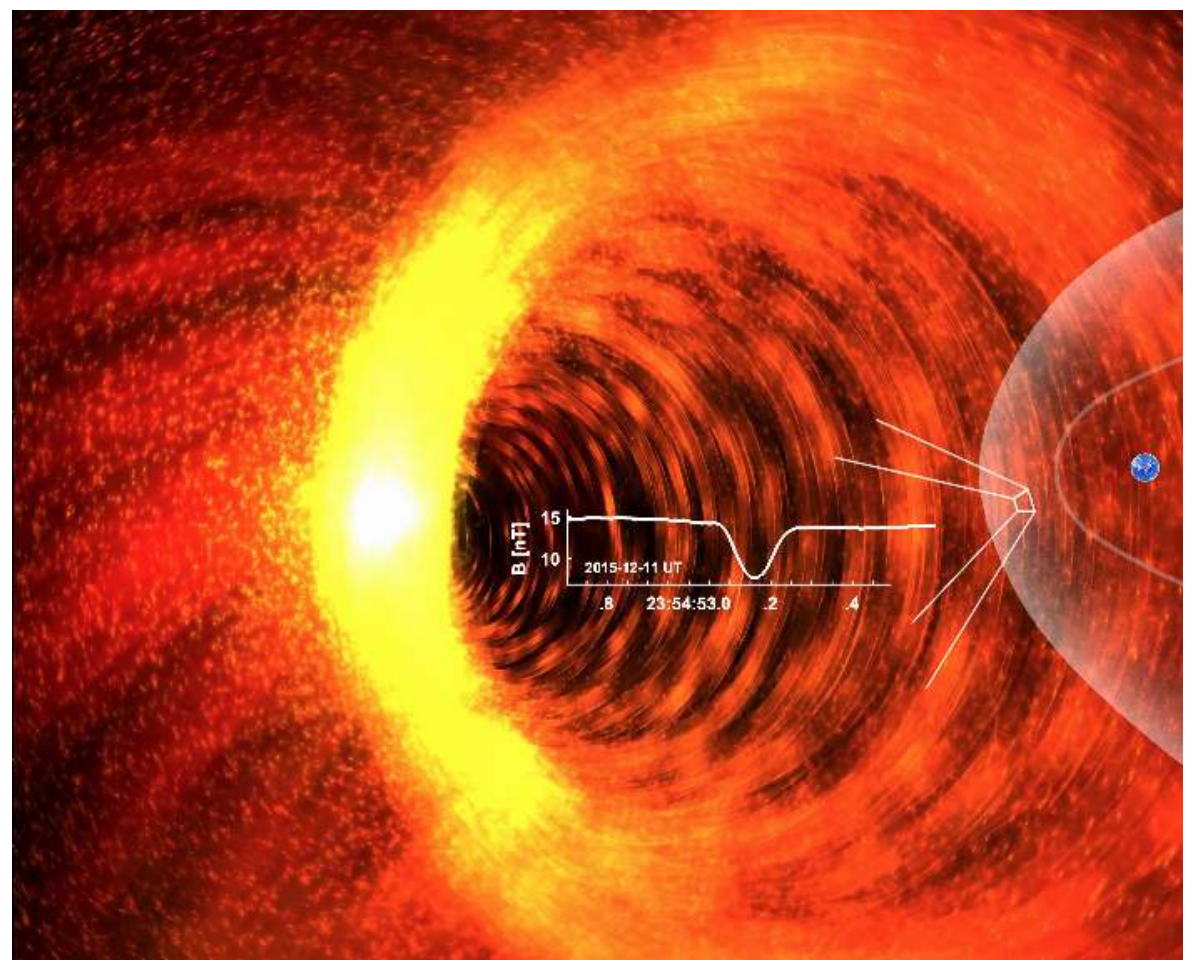

Figure 1. A schematic of a $\mathrm{KSMH}$ and a typical $\mathrm{KSMH}$ observed in the magnetosheath by MMS. 
ler mode waves, including wave formation, dispersion, and growth rates, was also studied by Huang SY et al. $(2018,2019)$. Zhong $\mathrm{ZH}$ et al. (2019) reported a KSMH event associated with strong energy dissipation near the active $X$ line at the dayside magnetopause. They suggested that the KSMH probably provided an additional channel for energy dissipation besides that of the electron diffusion region. The MMS mission also revealed new features of KSMHs observed in the Earth's magnetotail and solar wind. For example, electron dynamics (diamagnetic and $E \times B$ drift) in KSMHs were investigated by Gershman et al. (2016) and Goodrich et al. (2016). The distributions of KSMHs exhibited dawn-dusk asymmetry in the magnetotail, with $\sim 72 \%$ of the KSMHs accompanied by substorms (Huang SY et al., 2019). Trainlike KSMHs were observed in the solar wind, and clear evidence indicated that they were electron mirror mode structures (Yao ST et al., 2019b). The generation, geometry, and particle behaviors of the solar wind $\mathrm{KSMH}$ s were further studied by Wang GQ et al. (2020b, c, d).

As indicated above, $\mathrm{KSMHs}$ with their generation mechanisms, effects, and impacts have been extensively investigated because of their importance and potential roles in the space environment. However, there remain difficult open questions regarding their structure source, generation environment, and spatio-temporal characteristics. For example, although KSMHs can be observed in both solar wind and the magnetosheath, to date it has not been clear whether some fraction of KSMHs are generated locally in the magnetosheath or whether they are all carried into the magnetosheath by the solar wind. What are their spatio-temporal characteristics and what are the underlying physical processes that generate and maintain their structure? In this article, we investigate these questions by carrying out a statistical study of the KSMHs observed by the MMS mission. The data set and event selection are introduced in Section 2. The distributions of the KSMHs's occurrence rate, amplitude, and temporal and spatial scales are shown in Section 3. A discussion and conclusions are presented in Section 4.

\section{Data and Event Selection}

Although the MMS burst mode data were widely and well used in previous studies, only $\sim 2 \%-4 \%$ of the time per day of burst mode data can be downloaded to the ground (Fuselier et al., 2016). The lower time resolution (fast and survey mode) MMS data from September 2015 to March 2020 are used in this study, since these data cover most of the orbit. The time resolution of survey mode magnetic field data from the Fluxgate Magnetometer (FGM) instrument is $16 \mathrm{~Hz}$ (Russell et al., 2016), and of the fast mode ion data from the Fast Plasma Investigation (FPI) instrument is $0.22 \mathrm{~Hz}$ (Pollock et al., 2016). The Geocentric Solar Ecliptic (GSE) coordinate system is used throughout this article.

An automated routine is used to select KSMHs by computing the average and minimum magnetic field strengths, $\left|B_{\text {ave }}\right|$ and $\left|B_{\min }\right|$ within a time window of $5 \mathrm{~s}$. Events with $\left|B_{\min }\right| /\left|B_{\text {ave }}\right| \leq 0.75$, and $\omega \leq 15^{\circ}$ are retained, where $\omega$ is the angle between the magnetic field vector averaged over a $1 \mathrm{~s}$ interval before and after the structure. Similar event selection criteria can be found in Zhang TL et al. (2008), Yao et al. (2017), and Huang SY et al. (2019). Further- more, additional conditions are attached to ensure that the selected events are more likely to be $\mathrm{KSMHs:} 1$ ) a relatively stable environment $\left(\left|B_{\text {ave }}\right| / \sigma_{B} \geq 2\right.$ and $\sigma_{B} \leq 5 \mathrm{nT}$, where $\sigma_{B}$ is the magnetic field standard deviation over the time window), 2) a significant magnetic field depression $\left(\left|B_{\text {ave }}\right|-\left|B_{\min }\right| \geq \sigma_{B}\right)$, and 3) a minimum time duration of the structure ( $\Delta t \geq 0.125 \mathrm{~s}$, e.g., the structure is identified by at least two data points, where $\Delta t$ is the structure duration when $\left.B \leq B_{\text {ave }}-\sigma_{B}\right)$. Approximately 0.2 million $(192,655)$ events were selected under these criteria over $\sim 1672$ days of available MMS data.

\section{Statistical Results and Analysis}

\subsection{Occurrence Rate}

For the statistical study of the occurrence rate of KSMHs in terrestrial space, one important issue is to take into account the amount of time the satellites spend in a given region of space. That is, a high number of events in some regions may be caused by repeated satellite passes through this region; on the other hand, a low number may be due to the fact that the satellites seldom passed there. It is therefore necessary to calculate the number of events normalized by the "orbit density", which has not been done in previous studies. The orbital density is defined as the number of times (counts) the satellite remained within an area of $1 R_{\mathrm{E}}^{2}$ of a given location ( $X_{\mathrm{GSE}}, Y_{\mathrm{GSE}}$ ) for a duration of 5 minutes (Figure 3a). Figure 2a shows the number of KSMHs normalized by orbit density. The color for each bin in Figure $2 a$ is the quantity of $\mathrm{KSMHs}$ observed by MMS in $1 R_{\mathrm{E}}^{2}$ per 5 mins (counts $/ \mathrm{R}_{\mathrm{E}}^{2} / 5$ mins) in the GSE $X-Y$ plane. Three areas can be clearly identified: the solar wind, magnetosheath, and magnetotail. Three examples observed in these areas are shown below (Figures $2 b-d)$ ). We mark three regions in Figure $2 a(R 1, R 2$, and R3) for quantitative comparisons. Region 1 is used mainly to compare the occurrence rate of KSMHs in the solar wind, magnetosheath, and magnetotail. Regions 2 and 3 can be used to compare the occurrence rate between the dawn and dusk sides in the magnetosheath and magnetotail. The average values of each region are shown in Figures 3c-e. Significantly, we find that the number of KSMHs observed in the magnetosheath is greater than that in the solar wind and magnetotail (Figure 3c). This demonstrates that most of the $\mathrm{KSMH}$ s observed in the magnetosheath are generated locally, instead of propagating into the magnetosheath along with the solar wind. It is worth noting that the structure motion speed is also an important factor. In other words, the faster the structure moves, the more structures the satellite could observe. Thus, the occurrence rate in Figure $2 \mathrm{a}$ is further normalized by the background plasma flow velocity, where we assume that the structure is non-propagating in the plasma flow. The result is consistent with Figure $2 \mathrm{a}$ and shown in the Supplementary Materials (Figure S1).

From Figures 2a and 3d, one can find that there are more KSMHs in the dawnside magnetosheath than in the duskside. It is well known that the magnetosheath is more turbulent downstream of the quasi-parallel shock $\left(Q_{/ /}\right)$than it is behind the spatially extended quasi-perpendicular shock $\left(Q_{\perp}\right)$ (e.g., Lucek et al., 2005). We examined the interplanetary magnetic field (IMF) conditions for each event in our study. Most of the time, the IMF configuration 

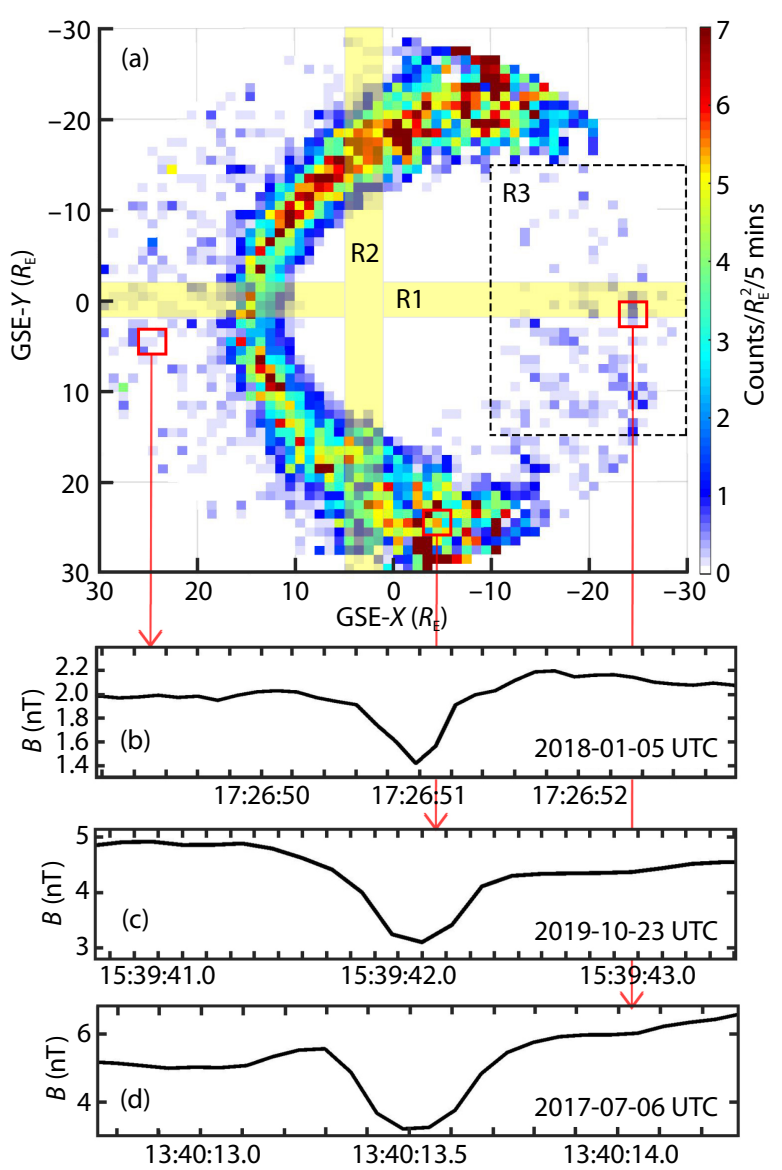

Figure 2. (a) The occurrence rate of KSMHs normalized by the orbit density (Figure 3a). The color indicates the number of observed $\mathrm{KSMHs}$ in $1 R_{\mathrm{E}}^{2}$ per 5 mins (counts $/ R_{\mathrm{E}}^{2} / 5$ mins). Examples in the solar wind, magnetosheath flank, and magnetotail are shown in (b-d). Three regions ( $R 1, R 2$, and $R 3$ ) are marked for quantitative comparisons, and details can be found in Figures 3 (c-e).

can be considered to be that of a Parker spiral (Figure 3b). Thus, the dawnside magnetosheath can be roughly considered as downstream of $Q_{/ /}$, and is more turbulent than the duskside magnetosheath. The statistical results in Figure $2 \mathrm{a}$ and Figure $3 \mathrm{~d}$ are consistent with the argument that $\mathrm{KSMH}$ s tend to be generated in more turbulent environments. Furthermore, a significant dawndusk asymmetry (duskside dominating) is found in the magnetotail (Figure 3e). This feature has been discussed by Huang SY et al. (2019); however, since MMS burst mode data were used, few events were observed in their study. The statistical results normalized by the orbit density in our study are consistent with and confirm the findings of Huang SY et al. (2019).

Figure 4 displays the statistical results of 1-min-averaged environmental parameters (magnetic field and ion velocity) for the $\mathrm{KSMH}$ events in region $\mathrm{R} 3$. One can observe that the distributions of the magnetic field on the dawnside and duskside are similar; however, there are significant differences in event counts (Figure $4 \mathrm{a}-\mathrm{c})$. The $X_{\mathrm{GSE}}$ and $Y_{\mathrm{GSE}}$ components of the magnetic field $\left(B_{x}, B_{y}\right)$ are distributed nearly symmetrically around zero (Figure $4 a, b$ ), and the $Z_{\mathrm{GSE}}$ component of the magnetic field $\left(B_{z}\right)$ is mainly positive (Figure $4 c, 89.5 \%$ on the dawnside and $83.3 \%$ on the duskside).
Generally, $B_{z}$ within the magnetotail plasma sheet is nearly northward because the magnetic fluxes emanate from the southern hemisphere and converge into the northern hemisphere. However, southward (negative) $B_{z}$ can also be observed in the plasma sheet because of magnetic reconnection (e.g., Øieroset et al., 2001), flux ropes and plasmoids (e.g., Slavin et al., 1995), and magnetic disturbances caused by current disruption (e.g., Lui, 1996). Hence, to some extent, areas where magnetic activity occurs can be indicated by southward $B_{z}$. In our study, although the distributions of $B_{z}$ on the dawnside and duskside are similar, there is still a significant difference in negative $B_{z}$ between the duskside (16.7\%) and dawnside (10.5\%). This indicates that the dawn-dusk asymmetry of KSMHs in the magnetotail may be related to magnetic activity regions. Furthermore, the average value of positive $B_{z}$ on the duskside ( $\left.2.6 \mathrm{nT}\right)$ is less than on the dawnside ( $3.6 \mathrm{nT})$, implying that the duskside magnetic field curvature radius is smaller and its current sheet is thinner (e.g., Büchner and Zelenyi, 1989; Rong ZJ et al., 2011). This thin current sheet is considered to be generated by a stronger Hall effect on the duskside (e.g., Lu S et al., 2019). Huang SY et al. (2019) also suggested that the dawn-dusk asymmetry of KSMHs in the magnetotail could be caused by the Hall effect. In Figure 4d, we find that the velocity in the $X_{\mathrm{GSE}}$ direction $\left(V_{x}\right)$ is mainly Earthward $(77.6 \%$ on the dawnside and $69.5 \%$ on the duskside). Furthermore, $36.1 \%$ and $22.8 \%$ of these events have velocities greater than $300 \mathrm{~km} / \mathrm{s}$ and $400 \mathrm{~km} / \mathrm{s}$, respectively. This indicates that some events are related to magnetic reconnection, which is an important mechanism for producing high-speed flows in Earth's magnetotail. In Figure 4f, the velocities of the $Z_{\text {GSE }}$ component $\left(V_{z}\right)$ are distributed similarly between dawnside and duskside. Significantly in Figure $4 \mathrm{e}$, the velocities of the $Y_{\text {GSE }}$ component $\left(V_{y}\right)$ in dawnside are distributed symmetrically around $V_{y}=0$, while a greater proportion $(70.1 \%)$ of events on the duskside have $V_{y}>0$. It can be seen that the velocity of events whose counts on the duskside exceed the dawnside are mainly distributed in $V_{y}>0$ (89.2\% of the total difference). This indicates a close relationship between the KSMHs and $V_{y}$. However, based on the current data, we cannot draw a conclusion with any certainty about the underlying physical processes involved. If the dawn-dusk asymmetry is caused by the near-Earth flow deflection, it indicates that a possible relationship with positive $V_{y}$, because the distribution of $V_{y}$ for the dawnside events is basically symmetric. Another possible scenario is related to the location of magnetically active regions. For example, activities such as magnetic reconnection are more frequent on the duskside, and may generate more KSMH events that are observed in the deflection flows by spacecraft.

\subsection{Scales and Depths}

To uncover the characteristics of the magnetosheath KSMHs, the scales and depths of the structures are studied. Machine learning is used to identify the duration of MMS located in the dayside magnetosheath proper (Freund and Schapire, 1997). These magnetosheath time intervals are chosen to be longer than 5 mins in duration and limited to instances when MMS was in the dayside $(R x>0)$. The KSMHs belonging to these periods are selected (in total 78, 503 events), and the average value of their scales and depths in each $\left(X_{\mathrm{GSE}}, Y_{\mathrm{GSE}}\right)$ bin are shown in Figure $5 \mathrm{a}-\mathrm{c}$. The spa- 

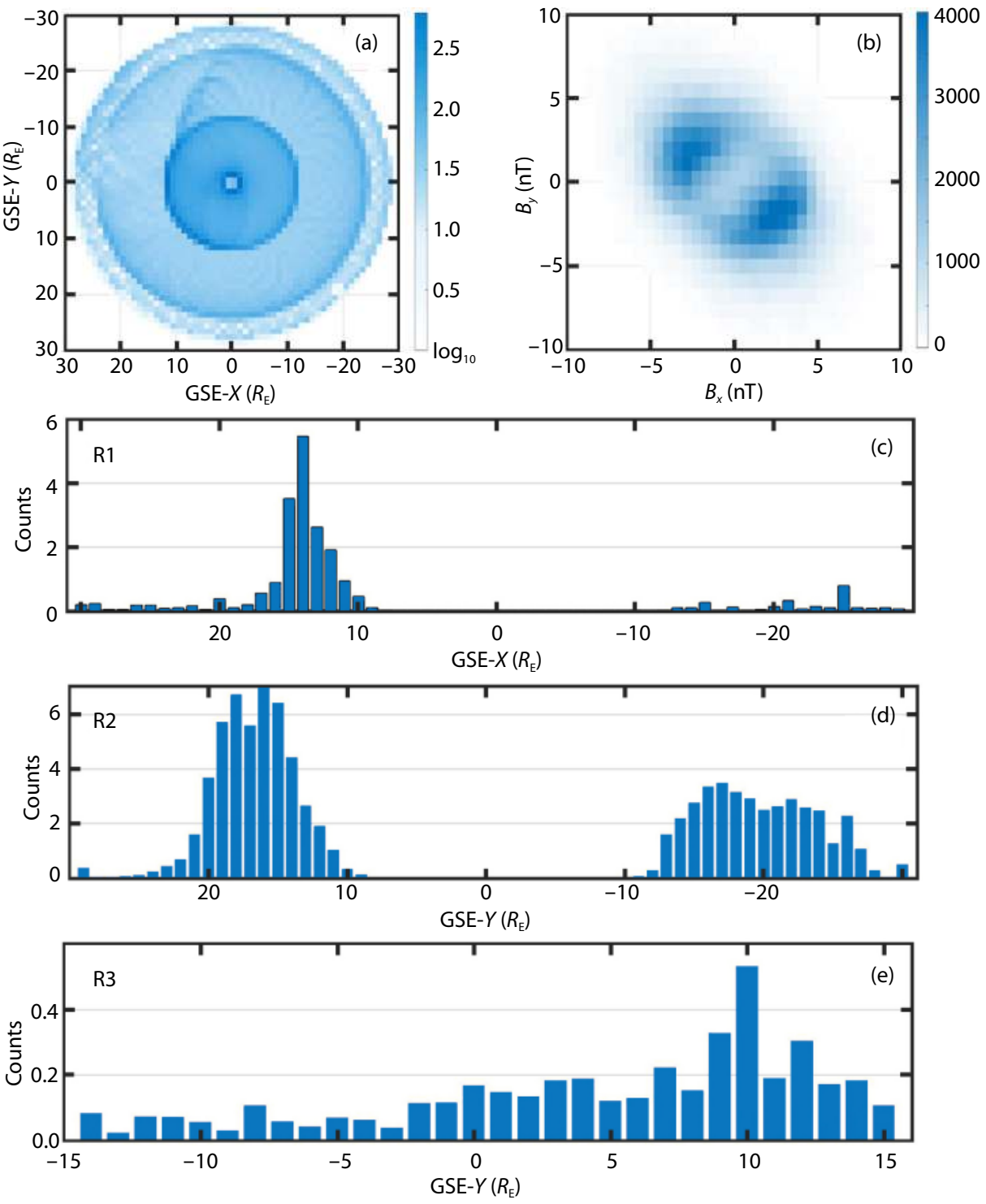

Figure 3. (a) The orbital density, defined as the counts of 5 -minute intervals in which a satellite is located within a $1 R_{\mathrm{E}}{ }^{2}\left(X_{\mathrm{GSE}}, Y_{\mathrm{GSE}}\right)$ rectangular bin. (b) Statistical results for the IMF conditions during each event. (c-e) Details for the regions marked in Figures 2a.

tial-scale is calculated from $V_{\mathrm{i}} \cdot \Delta t / \rho_{\mathrm{i}}$, assuming the structure is propagating with the plasma flow, where $V_{\mathrm{i}}$ is the 1-min-averaged ion bulk velocity of MMS1, and $\Delta t$ is the structure duration (temporal-scale). The ion gyroradius $\rho_{\mathrm{i}}$ is calculated from 1minaveraged magnetic field and ion temperature measurement of MMS1. Figure 5 a shows that the temporal-scales of the KSMHs increase when close to the magnetosphere, and Figure $5 \mathrm{~b}$ shows that the spatial-scale near the subsolar magnetosheath is smaller than that in the flanks. Figure $5 c$ plots the depth $\left(\left(1-\left|B_{\min }\right| /\right.\right.$ $\left.\left|B_{\text {ave }}\right|\right) \times 100 \%$ ) of the KSMHs and suggests that the KSMHs become shallower from the bow shock to the magnetopause; however, this feature is not very obvious. The plasma beta and Mach number are also important parameters for the investigation of KSMHs. For example, if the bow shock is a $Q_{\perp}$ shock, the high beta and Mach number region is more turbulent in the magnetosheath. Here we show the statistical results of the beta and Mach number in Figure $5 d$ and 5 e. One can see that the distributions of beta and Mach number are basically symmetric in the magnetosheath, suggesting that they may not play a major role in the asymmetric $\mathrm{KSMH}$ occurrence rate between the regions downstream of $Q_{/ /}$and $Q_{\perp}$. The value of beta in the subsolar magnetosheath is greater than in the flanks, while the opposite is the case for the Mach number. This is basically as expected for the physical processes occurring in the magnetosheath. Considering the compression of magnetic fluxes in different regions, and that the scale is smaller when it is normalized by $\rho_{\mathrm{i}}$ in a high beta environment, we can infer that the KSMHs appear to be compressible. The available data, however, do not provide a definitive analysis. A more detailed analysis is necessary - for example, to calculate and normalize the distance from each event to the bow shock and magnetosphere, and to compare the position of each event with its characteristics. Another possibility that could be tried in the future would be to normalize the structure location using a 2-D model of solar wind plasma flow/convection around the magnetopause and carry out the analysis based on streamlines.

Here we also need to discuss the uncertainty of the spatial and 

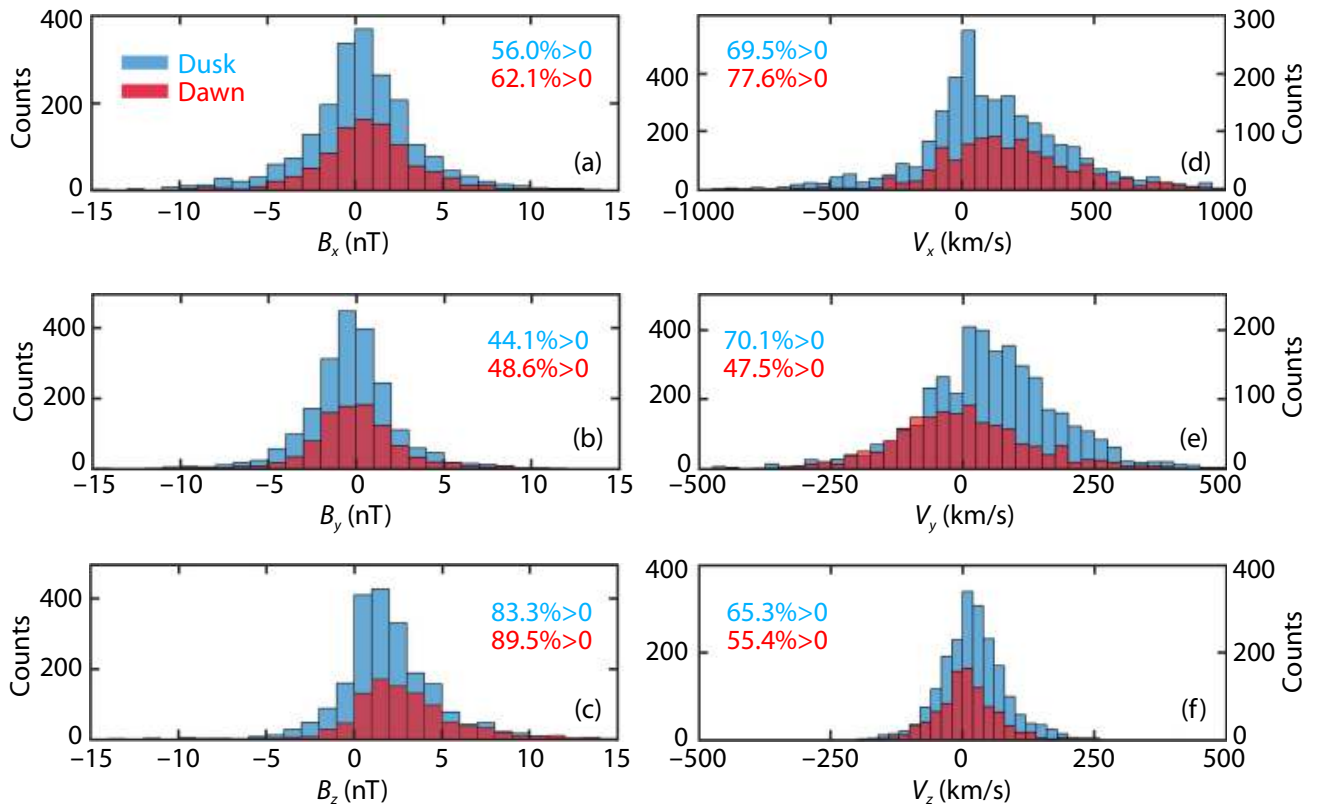

Figure 4. Statistical results of 1-min-averaged environmental parameters (magnetic field and ion velocity) for the KSMH events in region R3.
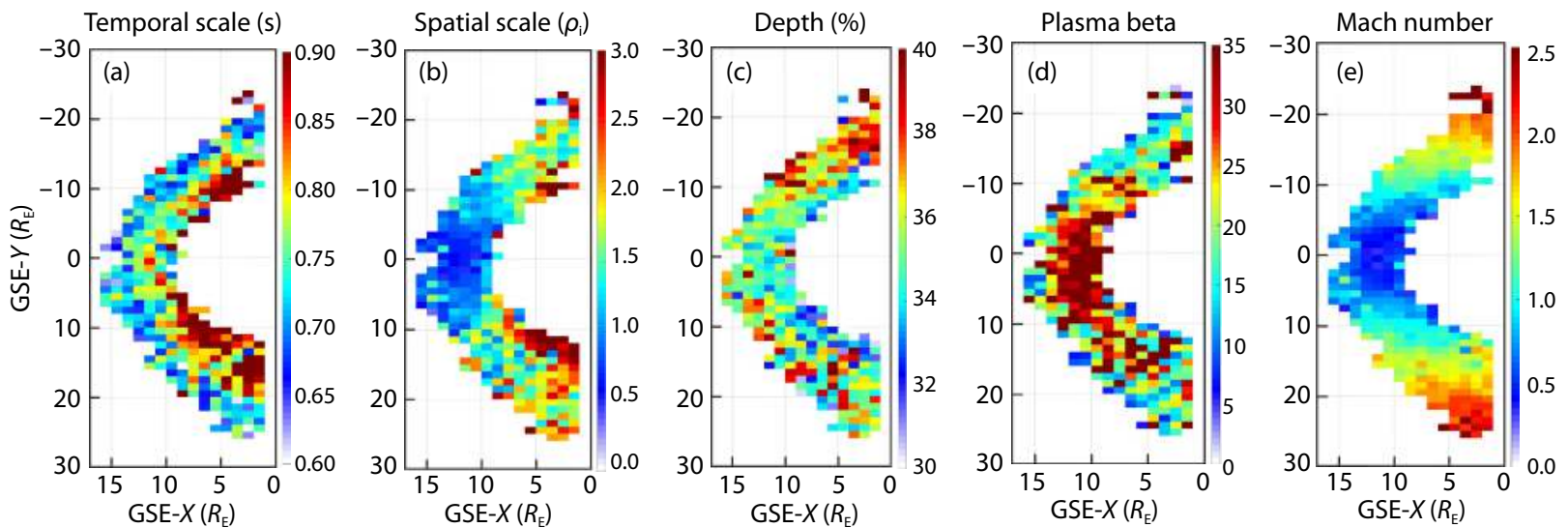

Figure 5. The averaged parameters in each bin for the KSMHs in the magnetosheath proper.

temporal scales. Since the temporal-scale $(\Delta t)$ is the duration when the magnetic field strength is lower than $\left|B_{\text {ave }}\right|$, the uncertainty of $\Delta t$ has been taken into account in the criterion that $\left|B_{\text {ave }}\right|-\left|B_{\min }\right| \geq \sigma_{B}$, where $\sigma_{B}$ is used to represent the uncertainty of $\left|B_{\text {ave }}\right|$. That is, the uncertainty of $\Delta t$ is the duration when the magnetic field strength is between $\left|B_{\text {ave }}\right|-\sigma_{B}$ and $\left|B_{\text {ave }}\right|+\sigma_{B}$. Because we need to make sure that the selected duration is indeed the duration of the structure, the lower limit of uncertainty is used in this study $\left(\left|B_{\min }\right| \leq\left|B_{\text {ave }}\right|-\sigma_{B}\right)$. For the spatial-scale, the uncertainties come from the ion bulk velocity, magnetic field, and ion temperature. The standard deviations of these parameters over $1 \mathrm{~min}$ were calculated for the events, and used to calculate the uncertainty in spatial-scale. We find that $68.3 \%, 87.2 \%$, and $93.4 \%$ of the events have uncertainties less than $10 \%, 20 \%$, and $30 \%$, respectively. This indicates that most of the spatial-scale uncertainties of the events are small and do not affect the results.

\section{Summary and Discussion}

In this study, KSMHs detected by MMS in near-Earth space are statistically analyzed. The main results are:

(1) The occurrence rate of KSMHs in the magnetosheath is far above that in the solar wind.

(2) The occurrence rate of KSMHs downstream of $Q_{/ /}$is higher than that of $Q_{\perp}$.

(3) The occurrence rate of KSMHs in the magnetotail exhibits a dawn-dusk asymmetry (duskside dominating).

(4) The temporal-scales of KSMHs increase as their depth is decreased when close to the dayside magnetopause.

(5) The spatial-scales of KSMHs near the subsolar magnetosheath are smaller than in the flanks.

These results indicate that most of the $\mathrm{KSMHs}$ in the magnetosheath are generated locally, rather than advected with the solar wind. The asymmetry of the occurrence rate between the downstream of $Q_{/ /}$and $Q_{\perp}$ is important evidence that $\mathrm{KSMHs}$ tend to be generated in more turbulent environments.

Studying the evolution of KSMHs is challenging. Their small scale and short duration make it difficult to investigate their structure 
by satellite observations. For example, it is hard for two satellites to observe the same structure at different times unless they are extremely close together. For satellite constellations (with e.g., MMS and Cluster), it is therefore hard to know whether the observations given by different satellites indicate temporal evolution or spatial-variations of observed structures. To study this issue, one possible way is to investigate statistically their structure properties and their relation to the background plasma environment. From Figure 5b one can observe that the structures' spatial-scale at the flanks are larger than when they are observed near the subsolar magnetosheath. It is known that the pressure near the subsolar magnetosheath is higher than in the flanks. A possible scenario is that the structure's spatial-scale is affected by its local pressure environment. A previous study has found that pressure variation can significantly affect how structures contract or expand, affecting their scale (Yao ST et al., 2020a), which supports the above deduction. That said, the spatial-scales near the magnetopause downstream of $Q_{\perp}$ are larger than in other positions - an observation that is worthy of further study.

\section{Supplementary Materials}
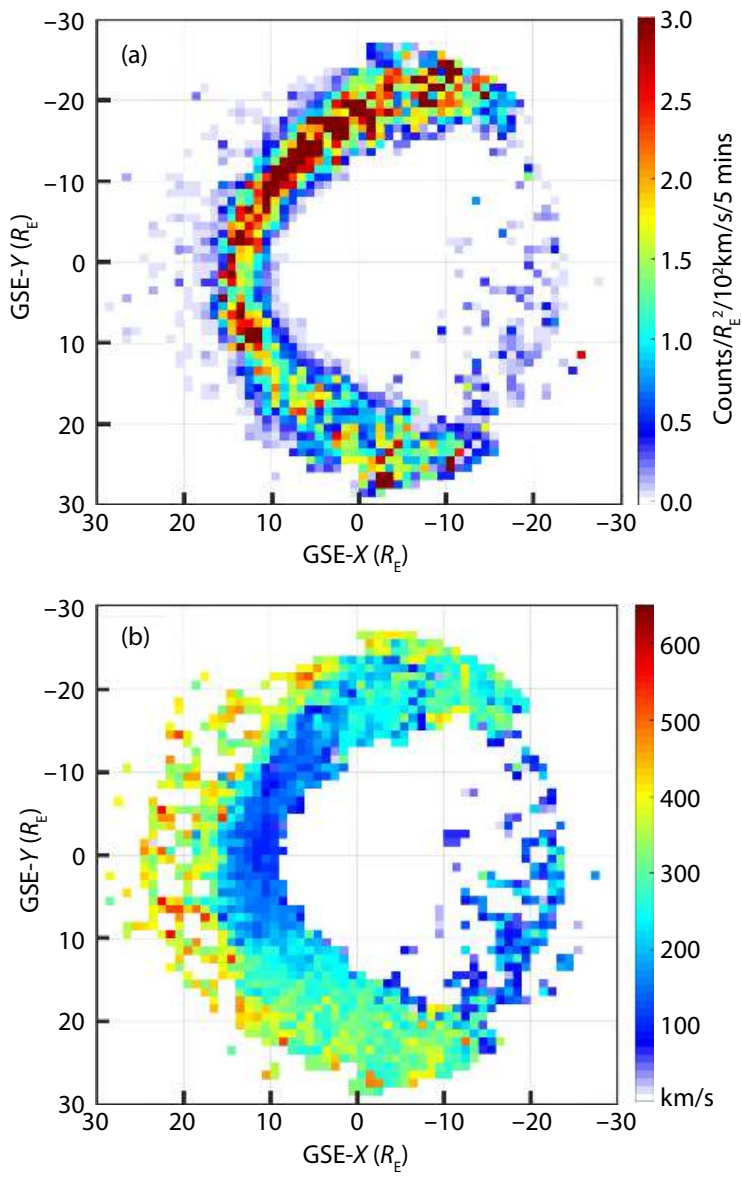

Figure S1. (a) The occurrence rate of KSMHs normalized by the orbit density and structure velocity. Here we assume that the KSMHs are non-propagating in the plasma flow, and use 1-min-averaged background plasma flow velocity (b) instead of structure velocity. The color indicates the number of observed $\mathrm{KSMHs}$ in $1 R_{\mathrm{E}}^{2}$ per $10^{2} \mathrm{~km} / \mathrm{s}$ per 5 mins (counts/ $R_{\mathrm{E}}^{2} / 10^{2} \mathrm{~km} / \mathrm{s} / 5$ mins).

\section{Acknowledgments}

We thank the MMS and AMDA teams for providing science data (https://lasp.colorado.edu/mms/sdc/public/; http://amda.cdpp. $\mathrm{eu} /$ ). This work was supported by the National Natural Science Foundation of China (grants 41731068, 41774153, 41941001, 41961130382, 41431072, and 41704169) and Royal Society NAF\R1 191047 . We thank the International Space Science Institute (ISSI) for their support. Z. H. Y. is supported by the PRODEX program managed by ESA in collaboration with the Belgian Federal Science Policy Office.

\section{References}

Balikhin, M. A., Sagdeev, R. Z., Walker, S. N., Pokhotelov, O. A., Sibeck, D. G., Beloff, N., and Dudnikova, G. (2009). THEMIS observations of mirror structures: magnetic holes and instability threshold. Geophys. Res. Lett., 36(3), L03105. https://doi.org/10.1029/2008GL036923

Balikhin, M. A., Sibeck, D. G., Runov, A., and Walker, S. N. (2012). Magnetic holes in the vicinity of dipolarization fronts: mirror or tearing structures?. J. Geophys. Res., 117(A8), A08229. https://doi.org/10.1029/2012JA017552

Baumgärtel, K. (1999). Soliton approach to magnetic holes. J. Geophys. Res., 104(A12), 28295-28308. https://doi.org/10.1029/1999JA900393

Büchner, J., and Zelenyi, L. M. (1989). Regular and chaotic charged particle motion in magnetotaillike field reversals: 1 . Basic theory of trapped motion. J. Geophys. Res., 94(A9), 11821-11842. https://doi.org/10.1029/JA094iA09p11821

Burch, J. L., Moore, T. E., Torbert, R. B., and Giles, B. L. (2016). Magnetospheric multiscale overview and science objectives. Space Sci. Rev., 199(1), 5-21. https://doi.org/10.1007/s11214-015-0164-9

Cattaneo, M. B. B., Basile, C., Moreno, G., and Richardson, J. D. (1998). Evolution of mirror structures in the magnetosheath of Saturn from the bow shock to the magnetopause. J. Geophys. Res., 103(A6), 11961-11972. https://doi.org/10.1029/97JA03683

Freund, Y., and Schapire, R. E. (1997). A decision-theoretic generalization of online learning and an application to boosting. J. Comput. Syst. Sci., 55(1), 119-139. https://doi.org/10.1006/jcss.1997.1504

Fuselier, S. A., Lewis, W. S., Schiff, C., Ergun, R., Burch, J. L., Petrinec, S. M., and Trattner, K. J. (2016). Magnetospheric multiscale science mission profile and operations. Space Sci. Rev., 199(1-4), 77-103. https://doi.org/10.1007/s11214-014-0087-x

Ge, Y. S., McFadden, J. P., Raeder, J., Angelopoulos, V., Larson, D., and Constantinescu, O. D. (2011). Case studies of mirror-mode structures observed by THEMIS in the near-Earth tail during substorms. J. Geophys. Res., 116(A1), A01209. https://doi.org/10.1029/2010JA015546

Gershman, D. J., Dorelli, J. C., Viñas, A. F., Avanov, L. A., Gliese, U., Barrie, A. C., Coffey, V., Chandler, M., Dickson, C., ... Burch, J. L. (2016). Electron dynamics in a subproton-gyroscale magnetic hole. Geophys. Res. Lett., 43(9), 4112-4118. https://doi.org/10.1002/2016GL068545

Goodrich, K. A., Ergun, R. E., Wilder, F. D., Burch, J., Torbert, R., Khotyaintsev, Y., Lindqvist, P. A., Russell, C., Strangeway, R., ... Malaspina, D. M. (2016). MMS multipoint electric field observations of small-scale magnetic holes. Geophys. Res. Lett., 43(12), 5953-5959. https://doi.org/10.1002/2016GL069157

Haynes, C. T., Burgess, D., Camporeale, E., and Sundberg, T. (2015). Electron vortex magnetic holes: A nonlinear coherent plasma structure. Phys. Plasmas, 22(1), 012309. https://doi.org/10.1063/1.4906356

Hellinger, P., and Štverák, Š. (2018). Electron mirror instability: particle-in-cell simulations. J. Plasma Phys., 84(4), 905840402. https://doi.org/10.1017/S0022377818000703

Huang, J., Zhou, M., Li, H. M., Deng, X. H., Liu, J., and Huang, S. Y. (2019). Smallscale dipolarization fronts in the Earth's magnetotail. Earth Planet. Phys., 3(4), 358-364. https://doi.org/10.26464/epp2019036

Hoilijoki, S., Ergun, R. E., Schwartz, S. J., Eriksson, S., Wilder, F. D., Webster, J. M., Ahmadi, N., Le Contel, O., Burch, J. L., ... Giles, B. L. (2019). Electron-scale 
magnetic structure observed adjacent to an electron diffusion region at the dayside magnetopause. J. Geophys. Res., 124(12), 10153-10169.

https://doi.org/10.1029/2019JA027192

Horbury, T. S., Lucek, E. A., Balogh, A., Dandouras, I., and Rème, H. (2004). Motion and orientation of magnetic field dips and peaks in the terrestrial magnetosheath. J. Geophys. Res., 109(A9), A09209.

https://doi.org/10.1029/2003JA010237

Huang, S. Y., Sahraoui, F., Retino, A., Le Contel, O., Yuan, Z. G., Chasapis, A., Aunai, N., Breuillard, H., Deng, X. H., ... Burch, J. L. (2016). MMS observations of ion-scale magnetic island in the magnetosheath turbulent plasma. Geophys. Res. Lett., 43(15), 7850-7858. https://doi.org/10.1002/2016GL070033

Huang, S. Y., Du, J. W., Sahraoui, F., Yuan, Z. G., He, J. S., Zhao, J. S., Le Contel, O. Breuillard, H., Wang, D. D., ... Burch, J. L. (2017a). A statistical study of kinetic-size magnetic holes in turbulent magnetosheath: MMS observations. J. Geophys. Res., 122(8), 8577-8588.

https://doi.org/10.1002/2017JA024415

Huang, S. Y., Sahraoui, F., Yuan, Z. G., He, J. S., Zhao, J. S., Le Contel, O., Deng, X. H., Zhou, M., Fu, H. S., ... Burch, J. L. (2017b). Magnetospheric multiscale observations of electron vortex magnetic hole in the turbulent magnetosheath plasma. Astrophys. J. Lett., 836(2), L27. https://doi.org/10.3847/2041-8213/aa5f50

Huang, S. Y., Sahraoui, F., Yuan, Z. G., Le Contel, O., Breuillard, H., He, J. S., Zhao, J. S., Fu, H. S., Zhou, M., ... Burch, J. L. (2018). Observations of whistler waves correlated with electron-scale coherent structures in the magnetosheath turbulent plasma. Astrophys. J., 861(1), 29. https://doi.org/10.3847/15384357/aac831

Huang, S. Y., He, L. H., Yuan, Z. G., Sahraoui, F., Le Contel, O., Deng, X. H., Zhou, M., Fu, H. S., Jiang, K., ... Burch, J. L. (2019). MMS observations of kinetic-size magnetic holes in the terrestrial magnetotail plasma sheet. Astrophys. J., 875(2), 113. https://doi.org/10.3847/1538-4357/ab0f2f

Jasinski, J. M., Arridge, C. S., Coates, A. J., Jones, G. H., Sergis, N., Thomsen, M. F., and Krupp, N. (2017). Diamagnetic depression observations at Saturn's magnetospheric cusp by the Cassini Spacecraft. J. Geophys. Res., 122(6), 6283-6303. https://doi.org/10.1002/2016JA023738

Ji, X. F., Wang, X. G., Sun, W. J., Xiao, C. J., Shi, Q. Q., Liu, J., and Pu, Z. Y. (2014). EMHD theory and observations of electron solitary waves in magnetotail plasmas. J. Geophys. Res., 119(6), 4281-4289. https://doi.org/10.1002/2014JA019924

Karimabadi, H., Roytershteyn, V., Vu, H. X., Omelchenko, Y. A., Scudder, J., Daughton, W., Dimmock, A., Nykyri, K., Wan, M., ... Geveci, B. (2014). The link between shocks, turbulence, and magnetic reconnection in collisionless plasmas. Phys. Plasmas, 21(6), 062308. https://doi.org/10.1063/1.4882875

Kitamura, N., Omura, Y., Nakamura, S., Amano, T., Boardsen, S. A., Ahmadi, N., Le Contel, O., Lindqvist, P. A., Ergun, R. E., ... Burch, J. L. (2020). Observations of the source region of whistler mode waves in magnetosheath mirror structures. J. Geophys. Res., 125(5), e2019JA027488. https://doi.org/10.1029/2019JA027488

Li, J. H., Yang, F., Zhou, X. Z. Zong, Q.-G., Artemyev, A. V., Rankin. R., Shi Q. Q., Yao S. T., Liu H., ... Burch. J. B. (2020a). Self-consistent kinetic model of nested electron- and ion-scale magnetic cavities in space plasmas. Nat Commun 11, 5616. https://doi.org/10.1038/s41467-020-19442-0

Li, J. H., Zhou, X. Z., Zong, Q.-G., Yang, F., Fu, S. Y., Yao, S. T., Liu. J., Shi. Q. Q. (2020b). On the origin of donut-shaped electron distributions within magnetic cavities. Geophysical Research Letters, 47(e2020GL091613). https://doi.org/10.1029/2020GL091613

Li, Z., Lu, Q. M., Wang, R. S., Gao, X. L., and Chen, H. Y. (2019). In situ evidence of resonant interactions between energetic electrons and whistler waves in magnetopause reconnection. Earth Planet. Phys., 3(6), 467-473. https://doi.org/10.26464/epp2019048

Li, Z. Y., Sun, W. J., Wang, X. G., Shi, Q. Q., Xiao, C. J., Pu, Z. Y., Ji, X. F., Yao, S. T., and Fu, S. Y. (2016). An EMHD soliton model for small-scale magnetic holes in magnetospheric plasmas. J. Geophys. Res., 121(5), 4180-4190. https://doi.org/10.1002/2016JA022424

Liu, H., Zong, Q.-G., Zhang, H., Xiao, C. J., Shi, Q. Q., Yao, S. T., He, J. S., Zhou, X. Z.,
Pollock, C., ... Rankin, R. (2019a). MMS observations of electron scale magnetic cavity embedded in proton scale magnetic cavity. Nat. Commun. 10(1), 1040. https://doi.org/10.1038/s41467-019-08971-y

Liu, H., Zong, Q.-G., Zhang, H., Sun, W. J., Zhou, X. Z., Gershman, D. J., Shi, C., Zhang, K., Le, G., and Pollock, C. (2019b). The geometry of an electron scale magnetic cavity in the plasma sheet. Geophys. Res. Lett., 46(16), 9308-9317. https://doi.org/10.1029/2019GL083569

Liu, Y. Y., Fu, H. S., Olshevsky, V., Pontin, D. I., Liu, C. M., Wang, Z., Chen, G., Dai, L., and Retino, A. (2019). SOTE: A nonlinear method for magnetic topology reconstruction in space plasmas. Astrophys. J. Suppl. Ser., 244(2), 31. https://doi.org/10.3847/1538-4365/ab391a

Liu, Y. Y., Fu, H. S., Zong, Q.-G., Wang, Z., Liu, C. M., Huang, S. Y., Chen, Z. Z., Xu, Y., Shi, Q. Q., and Yao, S. T. (2020). First topology of electron-scale magnetic hole. Geophys. Res. Lett., 47(18), e2020GL088374. https://doi.org/10.1029/2020GL088374

Lu, S., Artemyev, A. V., Angelopoulos, V., Lin, Y., Zhang, X. J., Liu, J., Avanov, L. A., Giles, B. L., Russell, C. T., and Strangeway, R. J. (2019). The Hall electric field in Earth's magnetotail thin current sheet. J. Geophys. Res., 124(2), 1052-1062. https://doi.org/10.1029/2018JA026202

Lucek, E. A., Dunlop, M. W., Balogh, A., Cargill, P., Baumjohann, W., Georgescu, E., Haerendel, G., and Fornacon, K. H. (1999). Mirror mode structures observed in the dawn-side magnetosheath by Equator-S. Geophys. Res. Lett., 26(14), 2159-2162. https://doi.org/10.1029/1999GL900490

Lucek, E. A., Constantinescu, D., Goldstein, M. L., Pickett, J., Pinçon, J. L., Sahraoui, F., Treumann, R. A, and Walker, S. N. (2005). The magnetosheath. Space Sci. Rev., 118(1-4), 95-152. https://doi.org/10.1007/s11214-005-3825-2

Lui, A. T. Y. (1996). Current disruption in the Earth's magnetosphere: observations and models. J. Geophys. Res., 101(A6), 13067-13088. https://doi.org/10.1029/96JA00079

Matsui, H., Farrugia, C. J., Goldstein, J., Torbert, R. B., Argall, M. R., Vaith, H., Russell, C. T., Strangeway, R. J., Giles, B. L., ... Hosokawa, K. (2019). Velocity rotation events in the outer magnetosphere near the magnetopause. J. Geophys. Res., 124(6), 4137-4156. https://doi.org/10.1029/2019JA026548

Øieroset, M., Phan, T. D., Fujimoto, M., Lin, R. P., and Lepping, R. P. (2001). In situ detection of collisionless reconnection in the Earth's magnetotail. Nature, 412(6845), 414-417. https://doi.org/10.1038/35086520

Plaschke, F., Karlsson, T., Götz, C., Möstl, C., Richter, I., Volwerk, M., Eriksson, A., Behar, E., and Goldstein, R. (2018). First observations of magnetic holes deep within the coma of a comet. Astron. Astrophys., 618, A114. https://doi.org/10.1051/0004-6361/201833300

Pollock, C., Moore, T., Jacques, A., Burch, J., Gliese, U., Saito, Y., Omoto, T., Avanov, L., Barrie, A., ... Zeuch, M. (2016). Fast plasma investigation for magnetospheric multiscale. Space Sci. Rev., 199(1-4), 331-406. https://doi.org/10.1007/s11214-016-0245-4

Rezeau, L., Belmont, G., Manuzzo, R., Aunai, N., and Dargent, J. (2018). Analyzing the magnetopause internal structure: New possibilities offered by MMS tested in a case study. J. Geophys. Res., 123(1), 227-241. https://doi.org/10.1002/2017JA024526

Rong, Z. J., Wan, W. X., Shen, C., Li, X., Dunlop, M. W., Petrukovich, A. A., Zhang, T. L., and Lucek, E. (2011). Statistical survey on the magnetic structure in magnetotail current sheets. J. Geophys. Res., 116(A9), A09218. https://doi.org/10.1029/2011JA016489

Roytershteyn, V., Karimabadi, H., and Roberts, A. (2015). Generation of magnetic holes in fully kinetic simulations of collisionless turbulence. Philos. Trans. Roy. Soc. A Math. Phys. Eng. Sci., 373(2041), 20140151. https://doi.org/10.1098/rsta.2014.0151

Russell, C. T., Riedler, W., Schwingenschuh, K., and Yeroshenko, Y. (1987). Mirror instability in the magnetosphere of comet Halley. Geophys. Res. Lett., 14(6), 644-647. https://doi.org/10.1029/GL014i006p00644

Russell, C. T., Anderson, B. J., Baumjohann, W., Bromund, K. R., Dearborn, D., Fischer, D., Le, G., Leinweber, H. K., Leneman, D., ... Richter, I. (2016). The magnetospheric multiscale magnetometers. Space Sci. Rev., 199(1-4), 189-256. https://doi.org/10.1007/s11214-014-0057-3

Sahraoui, F., Hadid, L., and Huang, S. Y. (2020). Magnetohydrodynamic and kinetic scale turbulence in the near-earth space plasmas: a (short) biased 
review. Rev. Mod. Plasma Phys., 4(1), 4. https://doi.org/10.1007/s41614-0200040-2

Shi, Q. Q., Shen, C., Pu, Z. Y., Dunlop, M. W., Zong, Q.-G., Zhang, H., Xiao, C. J., Liu, Z. X., and Balogh, A. (2005). Dimensional analysis of observed structures using multipoint magnetic field measurements: application to Cluster. Geophys. Res. Lett., 32(12), L12105. https://doi.org/10.1029/2005GL022454

Shang, W. S., Tang, B. B., Shi, Q. Q., Tian, A. M., Zhou, X. Y., Yao, Z. H., Degeling, A. W., Rae, I. J., Fu, S. Y., ... Wang, M. (2020). Unusual location of the geotail magnetopause near lunar orbit: a case study. J. Geophys. Res., 125(4), e2019JA027401. https://doi.org/10.1029/2019JA027401

Shi, Q. Q., Shen, C., Dunlop, M. W., Pu, Z. Y., Zong, Q.-G., Liu, Z. X., Lucek, E., and Balogh, A. (2006). Motion of observed structures calculated from multipoint magnetic field measurements: application to cluster. Geophys. Res. Lett., 33(8), L08109. https://doi.org/10.1029/2005GL025073

Shi, Q. Q., Pu, Z. Y., Soucek, J., Zong, Q.-G., Fu, S. Y., Xie, L., Chen, Y., Zhang, H., Li, L., ... Reme, H. (2009). Spatial structures of magnetic depression in the Earth's high-altitude cusp: cluster multipoint observations. J. Geophys. Res., 114(A10), A10202. https://doi.org/10.1029/2009JA014283

Shi, Q. Q., Tian, A. M., Bai, S. C., Hasegawa, H., Degeling, A. W., Pu, Z. Y., Dunlop, M., Guo, R. L., Yao, S. T., ... Liu, Z. Q. (2019). Dimensionality, coordinate system and reference frame for analysis of in-situ space plasma and field data. Space Sci. Rev., 215(4), 35. https://doi.org/10.1007/s11214-019-0601-2

Shustov, P. I., Zhang, X. J., Pritchett, P. L., Artemyev, A. V., Angelopoulos, V., Yushkov, E. V., and Petrukovich, A. A. (2019). Statistical properties of sub-ion magnetic holes in the dipolarized magnetotail: formation, structure, and dynamics. J. Geophys. Res., 124(1), 342-359. https://doi.org/10.1029/2018JA025852

Slavin, J. A., Owen, C. J., Kuznetsova, M. M., and Hesse, M. (1995). ISEE 3 observations of plasmoids with flux rope magnectic topologies. Geophys. Res. Lett., 22(15), 2061-2064. https://doi.org/10.1029/95GL01977

Song, P., Russell, C. T., and Thomsen, M. F. (1992). Slow mode transition in the frontside magnetosheath. J. Geophys. Res., 97(A6), 8295-8305. https://doi.org/10.1029/92JA00381

Song, P., Russell, C. T., and Gary, S. P. (1994). Identification of low-frequency fluctuations in the terrestrial magnetosheath. J. Geophys. Res., 99(A4), 6011-6025. https://doi.org/10.1029/93JA03300

Stasiewicz, K. (2004). Theory and observations of slow-mode solitons in space plasmas. Phys. Rev. Lett., 93(12), 125004.

https://doi.org/10.1103/PhysRevLett.93.125004

Stawarz, J. E., Eastwood, J. P., Genestreti, K. J., Nakamura, R., Ergun, R. E., Burgess, D., Burch, J. L., Fuselier, S. A., Gershman, D. J., ... Torbert, R. B. (2018). Intense electric fields and electron-scale substructure within magnetotail flux ropes as revealed by the Magnetospheric Multiscale mission. Geophys. Res. Lett., 45(17), 8783-8792. https://doi.org/10.1029/2018GL079095

Sun, W. J., Shi, Q. Q., Fu, S. Y., Pu, Z. Y., Dunlop, M. W., Walsh, A. P., Zong, Q.-G., Xiao, T., Tang, C. L., ... Fazakerley, A. (2012). Cluster and TC-1 observation of magnetic holes in the plasma sheet. Ann. Geophys., 30(3), 583-595. https://doi.org/10.5194/angeo-30-583-2012

Sun, W. J., Slavin, J. A., Tian, A. M., Bai, S. C., Poh, G. K., Akhavan-Tafti, M., Lu, S., Yao, S. T., Le, G., ... Burch, J. L. (2019). MMS study of the structure of ionscale flux ropes in the Earth's cross-tail current sheet. Geophys. Res. Lett., 46(12), 6168-6177. https://doi.org/10.1029/2019GL083301

Sundberg, T., Burgess, D., and Haynes, C. T. (2015). Properties and origin of subproton-scale magnetic holes in the terrestrial plasma sheet. J. Geophys. Res., 120(4), 2600-2615. https://doi.org/10.1002/2014JA020856

Tian, A. M., Shi, Q. Q., Degeling A. W., Bai, S. C., Yao, S. T., and Zhang, S. (2018). Analytical model test of methods to find the geometry and velocity of magnetic structures. Sci. China Technol. Sci., 62(6), 1003-1014. https://doi.org/10.1007/s11431-018-9350-1

Tian, A. M., Xiao, K., Degeling, A. W., Shi, Q. Q., Park, J. S., Nowada, M., and Pitkänen, T. (2020). Reconstruction of plasma structure with anisotropic pressure: application to Pc5 compressional wave. Astrophys. J., 889(1), 35. https://doi.org/10.3847/1538-4357/ab6296

Treumann, R. A., and Baumjohann, W. (2019). Electron pairing in mirror modes: surpassing the quasi-linear limit. Ann. Geophys., 37(4), 971-988. https://doi.org/10.5194/angeo-37-971-2019

Tsurutani, B. T., Lakhina, G. S., Verkhoglyadova, O. P., Echer, E., Guarnieri, F. L., Narita, Y., and Constantinescu, D. O. (2011). Magnetosheath and heliosheath mirror mode structures, interplanetary magnetic decreases, and linear magnetic decreases: differences and distinguishing features. J. Geophys. Res., 116(A2), A02103. https://doi.org/10.1029/2010JA015913

Turner, J. M., Burlaga, L. F., Ness, N. F., and Lemaire, J. F. (1977). Magnetic holes in the solar wind. J. Geophys. Res., 82(13), 1921-1924. https://doi.org/10.1029/JA082i013p01921

Wang, G. Q., Zhang, T. L., Wu, M. Y., Schmid, D., Hao, Y. F., and Volwerk, M. (2020a). Roles of electrons and ions in formation of the current in mirrormode structures in the terrestrial plasma sheet: Magnetospheric Multiscale observations. Ann. Geophys., 38(2), 309-318. https://doi.org/10.5194/angeo38-309-2020

Wang, G. Q., Zhang, T. L., Wu, M. Y., Hao, Y. F., Xiao, S. D., Wang, G., et al. (2020b). Study of the electron velocity inside sub-ion-scale magnetic holes in the solar wind by MMS observations. J. Geophys. Res., 125, e2020JA028386. https://doi.org/10.1029/2020JA028386

Wang, G. Q., Zhang, T. L., Xiao, S. D., Wu, M. Y., Wang, G., Liu, L. J., et al. (2020c). Statistical properties of sub-ion magnetic holes in the solar wind at $1 \mathrm{AU}$. J. Geophys. Res., 125, e2020JA028320. https://doi.org/10.1029/2020JA028320

Wang, G. Q., Volwerk, M., Xiao, S. D., Wu, M. Y., Hao, Y. F., Liu, L. J., Wang, G., Chen, Y. Q., and Zhang, T. L. (2020d). Three-dimensional Geometry of the Electron-scale Magnetic Hole in the Solar Wind. Astrophys. J. Lett., 904, L11. https://doi.org/10.3847/2041-8213/abc553

Wang, M. M., Yao, S. T., Shi, Q. Q., Zhang, H., Tian, A. M., Degeling, A. W., Zhang, S., Guo, R. L., Sun, W. J., ... Pu, Z. Y. (2020). Propagation properties of foreshock cavitons: cluster observations. Sci. China Technol. Sci., 63(1), 173-182. https://doi.org/10.1007/s11431-018-9450-3

Wang, S. M., Wang, R. S., Yao, S. T., Lu, Q. M., Russell, C. T., and Wang, S. (2019). Anisotropic electron distributions and whistler waves in a series of the flux transfer events at the magnetopause. J. Geophys. Res., 124(3), 1753-1769. https://doi.org/10.1029/2018JA026417

Xiao, T., Zhang, H., Shi, Q. Q., Zong, Q.-G., Fu, S. Y., Tian, A. M., Sun, W. J., Wang, S., Parks, G. K., ... Dandouras, I. (2015). Propagation characteristics of young hot flow anomalies near the bow shock: cluster observations. J. Geophys. Res., 120(6), 4142-4154. https://doi.org/10.1002/2015JA021013

Yao, S. T., Shi, Q. Q., Li, Z. Y., Wang, X. G., Tian, A. M., Sun, W. J., Hamrin, M., Wang, M. M., Pitkänen, T., ... Rème, H. (2016). Propagation of small size magnetic holes in the magnetospheric plasma sheet. J. Geophys. Res., 121(6), 5510-5519. https://doi.org/10.1002/2016JA022741

Yao, S. T., Wang, X. G., Shi, Q. Q., Pitkänen, T., Hamrin, M., Yao, Z. H., Li, Z. Y., Ji, X. F., De Spiegeleer, A., ... Liu, J. (2017). Observations of kinetic-size magnetic holes in the magnetosheath. J. Geophys. Res., 122(2), 1999-2000. https://doi.org/10.1002/2016JA023858

Yao, S. T., Shi, Q. Q., Guo, R. L., Yao, Z. H., Tian, A. M., Degeling, A. W., Sun, W. J., Liu, J., Wang, X. G., ... Liu, H. (2018a). Magnetospheric Multiscale observations of electron scale magnetic peak. Geophys. Res. Lett., 45(2), 527-537. https://doi.org/10.1002/2017GL075711

Yao, S. T., Shi, Q. Q., Liu, J., Yao, Z. H., Guo, R. L., Ahmadi, N., Degeling, A. W., Zong, Q.-G., Wang, X. G., ... Giles, B. L. (2018b). Electron dynamics in magnetosheath mirror-mode structures. J. Geophys. Res., 123(7), 5561-5570. https://doi.org/10.1029/2018JA025607

Yao, S. T., Shi, Q. Q., Yao, Z. H., Li, J. X., Yue, C., Tao, X., Degeling, A. W., Zong, Q.G., Wang, X. G., ... Giles, B. L. (2019a). Waves in kinetic-scale magnetic dips: MMS observations in the magnetosheath. Geophys. Res. Lett., 46(2), 523-533. https://doi.org/10.1029/2018GL080696

Yao, S. T., Shi, Q. Q., Yao, Z. H., Guo, R. L., Zong, Q.-G., Wang, X. G., Degeling, A. W., Rae, I. J., Russell, C. T., and Tian, A. M. (2019b). Electron mirror-mode structure: magnetospheric multiscale observations. Astrophys. J. Lett., 881(2), L31. https://doi.org/10.3847/2041-8213/ab3398

Yao, S. T., Hamrin, M., Shi, Q. Q., Yao, Z. H., Degeling, A. W., Zong, Q.-G., Liu, H., Tian, A. M., Liu, J., ... Giles, B. L. (2020a). Propagating and dynamic properties of magnetic dips in the dayside magnetosheath: MMS observations. J. Geophys. Res., 124(6), e2019JA026736. https://doi.org/10.1029/2019JA026736 
Yao, S. T., Shi, Q. Q., Guo, R. L., Yao, Z. H., Fu, H. S., Degeling, A. W., Zong, Q.-G., Wang, X. G., Russell, C. T., ... Giles, B. L. (2020b). Kinetic-scale flux rope in the magnetosheath boundary layer. Astrophys. J., 897(2), 137. https://doi.org/10.3847/1538-4357/ab9620

Zhang, L., He, J. S., Zhao, J. S., Yao, S., and Feng, X. S. (2018). Nature of magnetic holes above ion scales: a mixture of stable slow magnetosonic and unstable mirror modes in a double-polytropic scenario?. Astrophys. J., 864(1), 35. https://doi.org/10.3847/1538-4357/aad4aa

Zhang, T. L., Russell, C. T., Baumjohann, W., Jian, L. K., Balikhin, M. A., Cao, J. B., Wang, C., Blanco-Cano, X., Glassmeier, K. H., ... Vörös, Z. (2008). Characteristic size and shape of the mirror mode structures in the solar wind at 0.72 AU. Geophys. Res. Lett., 35(10), L10106.
https://doi.org/10.1029/2008GL033793

Zhang, X. J., Artemyev, A., Angelopoulos, V., and Horne, R. B. (2017). Kinetics of sub-ion scale magnetic holes in the near-Earth plasma sheet. J. Geophys. Res., 122(10), 10304-10317. https://doi.org/10.1002/2017JA024197

Zhong, Z. H., Zhou, M., Huang, S. Y., Tang, R. X., Deng, X. H., Pang, Y., and Chen, H. T. (2019). Observations of a kinetic-scale magnetic hole in a reconnection diffusion region. Geophys. Res. Lett., 46(12), 6248-6257.

https://doi.org/10.1029/2019GL082637

Zong, Q.-G., Fritz, T. A., Spence, H., Oksavik, K., Pu, Z. Y., Korth, A., and Daly, P. W. (2004). Energetic particle sounding of the magnetopause: a contribution by Cluster/RAPID. J. Geophys. Res, 109(A4), A04207.

https://doi.org/10.1029/2003JA009929 